and the fibrinolytic agent. They lysed human thrombin-fibrinogen clots in dilutions ranging as high as $1 / 3,000$. But when either the fibrinogen or fibrin was first heated to $60^{\circ} \mathrm{C}$. for half an hour to inactivate plasminogen, or when soya bean trypsin-inhibitor was added to the mixture there was no lysis.

Since soya bean trypsin-inhibitor inhibits plasmin but not bacterial proteases, it appears that the staphylococcus produces an activator of plasminogen and not a true fibrinolysin, and that its action is similar to that of streptokinase. This explains the absence of lysis with rabbit fibrin, since Christensen ${ }^{2}$ has shown that rabbit plasma contains an inhibitor, anti-plasmin.

It is unfortunate that there has been so much confusion over terminology in this field of investigation. The plasminogen and plasmin referred to here correspond to the pro-fibrinolysin and fibrinolysin of American workers ${ }^{3}$, and anti-plasmin to antifibrinolysin.

The action of staphylococci on the fibrin of other species is being investigated.

Lister Institute of Preventive Medicine,

Charles H. Lack Elstree, Herts.

$$
\text { Jan. } 1 .
$$

1 Maddison, R. R., Proc. Soc. Exp. Biol. Med., 33, 209 (1935).

'Christensen, L. R., J. Gen. Phys., 28, 363 (1945).

- Loomis, E. C., George, C., and Ryder, A., Arch. Biochem., 12, 1 (1947).

\section{Hæmolytic System in the Blood of Malaria-infected Monkeys}

THE isolation of a hæmolytic substance from normal human blood plasma has previously been reported ${ }^{1}$. It has so far been characterized as an unsaturated monocarboxylic fatty acid having one double bond and the possible chain-length C18. This substance has been found to be widely distributed and has been isolated in varying amounts from a large number of animal tissues, brain especially giving a high yield.

Antimalarial drugs inhibit specifically the hæmolytic activity of this fatty acid in vitro ${ }^{2}$. This fact led to the assumption that "the malaria parasites at some stage of their development produce a metabolite closely related to the naturally occurring hæmolytic substance, and that the effect of antimalarial drugs in vivo is bound up with their action on this meta. bolite". This hypothesis is now supported by further experimental data. Heavily parasitized (Plasmodium knowlesi) monkey blood has been examined as to its content of hæmolytic substance and has given a manifold higher yield $(25-75 \times)$ than normal monkey blood, varying with the degree and duration of the infection. The content of hæmolytic substance in parasitized blood is increased both inside the erythrocytes, which normally contain only little, and in the plasma. Microanalysis of the hæmolytic substance isolated in crystalline form from parasitized blood was made by Dr. G. Kenner, of the Chemical Laboratory, Cambridge, and so far has shown no difference from the hæmolytic substance obtained from normal blood and other tissues.

The malaria parasites, therefore, seem to produce or cause to appear inside the erythrocytes a hæmolytic substance, possibly identical with the physiological fatty acid, which destroys the erythrocytes when its concentration is high and is then released. into the plasma. The production of a hæmolytic substance by the parasites may be thought of as enabling the metabolic utilization of the constituents of the erythrocyte by the parasite and the release of the merozoites.

This mode of erythrocyte destruction by the parasite is accentuated by another parasitic metabolite, namely, the malaria pigment, which is a hæmatin compound. Hæmatin, which is not a normal break. down product of hæmoglobin, has itself been found to be hæmolytic in vitro in Iow concentrations down to $1 / 50,000$. In still lower, subhæmolytic concentrations $(1 / 200,000)$, it strongly potentiates the effect of the hæmolytic substance. In the light of these results, it might be interesting to study the quantitative relations of these two factors in the blood of blackwater fever cases.

I am indebted to Dr. F. Hawking, of the National Institute for Medical Research, London, for providing me with the samples of monkey blood used in these experiments. A detailed report will appear elsewhere.

Molteno Institute, H. LASER

University of Cambridge. Jan. 6.

${ }^{1}$ Laser, H., and Friedmann, E., Nature, 156, 507 (1945).

Laser, H., Nature, 157, 301 (1946).

\section{Nitrogen Metabolism After Fracture}

AFTER a severe injury, such as a fracture, nitrogen balance usually becomes negative and the body loses nitrogen. The extent to which local effects of the injury (damage to tissues and disuse atrophy of muscles) contribute to this outpouring of nitrogen appears to have received little attention. The only direct measurements of loss of tissue from fractured limbs are those of Cuthbertson, McGirr and Robertson $^{1}$, who studied rats. These investigators fractured one femur of each rat, and on the tenth day after injury the animals were killed and both hind limbs were weighed. The average difference in weight between the sound limb and the injured limb was $1.03 \mathrm{gm}$. Assuming the material lost from the injured limb to have been muscle, they calculated that this difference in weight was equivalent to a loss of $32 \cdot 2 \mathrm{mgm}$. nitrogen. There was, however, an average excess output of $425 \mathrm{mgm}$. nitrogen in the urine during the first nine days after fracture. From these observations it would seem that very little of the excess nitrogen excreted after fracture comes from the tissues of the injured limb.

We thought it desirable to repeat these experiments with certain modifications: first, the animals were killed five or six days after fracture, because it was thought that by the tenth day reparative processes may have partly compensated for earlier loss of tissue; secondly, direct determinations were made of the nitrogen lost from the injured limb, rather than indirectly by weighings of tissue. Two groups of rats receiving a 25 per cent casein diet were used, and the urinary collections and fracture technique were similar to those employed in previous experiments ${ }^{2}$. The first group of rats were killed five days after fracture, the second group six days after fracture. By this time the main phase of increased nitrogen excretion was ended in each group. The hind limbs were skinned and dissected from the trunk, using anatomical landmarks in order to achieve symmetrical removal of right and left limbs. After weighing, each limb was digested in concen- 